\title{
Possible protective role of L-thyroxin on the parotid gland of adult male albino rat in carbimazole induced hypothyroidism: histological, histomorphometry and ultrastructural study
}

\author{
Shaimaa A.R. Mostafa \\ Department of Anatomy and Embryology, Fayoum University, Egypt
}

\section{SUMMARY}

This study was carried out to throw more light on the histological, biochemical and immunohistochemical changes in the parotid gland of the adult male albino rat, following oral administration of Carbimazole and possible protective role of Levothyroxine sodium (L-Thyroxin). Fifty-five adult male albino rats (Sprague Dawley) were used. They were divided into four groups and eleven subgroups; five rats each; Animals were sacrificed and parotid specimens were processed for light and electron microscopic examination. Administration of Carbimazole resulted in significant damage in the parotid, which was more obvious with longer duration; most of the serous acini had irregular outlines, widely separated with narrow lumen and cytoplasmic vacuoles. Some acinar cells contained irregular, pyknotic or hyperchromatic nuclei. The interlobular and striated ducts appeared disrupted and dilated with cellular infiltration. Oral administration of L-Thyroxin significantly improves histological changes, expression of $\mathrm{B}$

Corresponding author:

Shaimaa A.R. Mostafa. Department of Anatomy and Embryology,

Fayoum University, Egypt. Phone: 01223698241. E-mail: Sar12@ fayoum.edu.eg cell lymphocyte (Bcl-2) and decrease collagen in Mallory-stained sections as were confirmed statistically. Induction of L-Thyroxin resulted in significant mitigating effects on damage of parotid gland. The results indicate that thyroid hormones administration causes parotid gland adaptation by augmenting endogenous antioxidants and protects rat parotid gland from oxidative stress associated with carbimazole-induced hypothyroidism and parotid gland atrophy.

Keywords: Thyroid hormones - Rat - Apoptosis - Carbimazole - Bcl-2

\section{INTRODUCTION}

Thyroid hormones (THs) are essential for physiological functions of almost all body tissues. They regulate reproductive functions, heart rate, body temperature, gastrointestinal motility and emotional stability. In addition, they control the metabolism of proteins, lipids and carbohydrates. Disruptions of thyroid function may produce

Submitted: June 10, 2021. Accepted: November 15, 2021

Not final proof's revision by the authors

https://doi.org/10.52083/BGEK9578 
various subclinical or clinical manifestations (Lamfon, 2014). THs are known to set the cellular basal metabolic rate, and are considered major regulators of energy metabolism, mitochondrial activity and biogenesi, oxygen consumption and active oxygen metabolism (Bhanja and Chainy, 2010). Thus, one of the most important functions performed by THs is the tight regulation of cellular oxygen consumption and consequent generation of reactive oxygen species (ROS) in several tissues (Petrulea et al., 2009), which can be attacked by the ROS for the initiation of lipid peroxidation (Vaidya et al., 2008). Hypothyroidism is one of the most common thyroid disorders, and may be congenital or acquired (Porth et al., 2004). It may result from dysfunction of the thyroid gland itself, impairment in mechanisms that control THs formation, or complications during treatment of hyperthyroidism. In humans, the hypothyroid state is a complex hormonal dysfunction rather than a single hormonal defect (Oncu et al., 2004), manifested largely by a reversible slowing down of all body functions (Dong, 2004).

Apart from general metabolic disturbance, impairment of THs production causes serious intellectual and behavioral abnormalities that may affect patient's daily functioning and result in additional stress and depression. Hypothyroid state led to increased levels of total cholesterol, low density lipoproteins and apolipoprotein B (El- Bassouny, 2012). It had been previously shown that THs increased the synthesis and mobilization of triglyceraldehydes stored in adipose tissue and lipoprotein-lipase activity (Pucci et al., 2000). Hypothyroidism is characterized by low metabolic rate resulting in adverse effect on many organs (Kiernan, 2015). Most of hypothyroid patients suffer from decreased gastrointestinal tract motility, malabsorption, loss of appetite and enlarged tongue (Rajab et al., 2017). It had been suggested that the parotid, the submandibular and in particular the sublingual glands were discernibly enlarged and served as a useful clue in the diagnosis of hypothyroidism (Fulop, 1989).

Apoptosis is a distinct process of cell death that is responsible for deletion of aged, injured and altered cells in normal and in certain specific pathologies like neoplasia. Indeed, the proper regulation of apoptosis is important in many aspects of life including development, homeostasis and disease biology (Khalawi et al., 2013). Bcl-2 family proteins are the regulators of apoptosis. Bcl-2 proteins have critical roles in normal cell physiology related to neuronal activity, autophagy, calcium handling, mitochondrial dynamics, energetics and other processes of normal healthy cells (Basanez and Hardwick, 2008). Bcl-2 family proteins consist of interacting partners includes inhibitors (anti-apoptotic) and inducers (pro apoptotic) of cell death. Together they regulate and mediate the process by which mitochondria contribute to cell death known as the intrinsic apoptosis pathway. This pathway is required for normal embryonic development and for preventing cancer (Basanez and Hardwick, 2008), so in the current work, immunohistochemical expression of Bcl-2 was performed. Hypothyroidism results in lower expression of Bcl-2 along with a high level of expression of Bax. These results suggest that THs promotes the expression of Bcl-2 genes, thus preventing apoptosis of early differentiating cells. However, under hypothyroid conditions, the downregulation of the anti-apoptotic Bcl-2 gene shifts the balance towards extensive apoptosis.

\section{MATERIALS AND METHODS}

\section{Chemicals}

Carbimazole (Neomercazol): is an antithyroid drug; obtained from Chemical Industries Development Co., Egypt; in a tablet form; each tablet contains $5 \mathrm{mg}$. The tablet was crushed, dissolved in saline ( $1 \mathrm{ml} / \mathrm{kg} ., \mathrm{bw})$ and given to the rats using gastric tube in a dose of $0.05 \mathrm{mg} / \mathrm{Kg}$, bw. daily (Dakine et al., 2000).

Levothyroxine sodium (L-Thyroxin): is a thyroxin hormone analogue, was obtained from Glaxo Welcome Co., Egypt, in a tablet form. Each tablet contains $50 \mu \mathrm{g}$. Each tablet was crushed and dissolved in saline ( $1 \mathrm{ml} / \mathrm{kg}$, bw) and was administered in a dose of $10 \mu \mathrm{g} / 100 \mathrm{~g}$ bw, orally using gastric tube daily (Dakine et al., 2000). 


\section{Animals}

Fifty-five adult male albino rats of Sprague Dawley strain, ageing 5-6 months, weighing 200250 g. each, were used in the present study. They were obtained from the animal house, Faculty of Medicine, Cairo University. They were housed in cages (5 rats per cage). All animals were kept in clean, properly ventilated cages, exposed to regular light cycles of 12/12-10/14 hours light and dark with room temperature range for rat housing between 20 and $26^{\circ} \mathrm{C}$, and were supplied with food and water ad libitum. Ethical Committee Permission number is: cu III f 1 19. The rats were divided randomly into four groups and eleven subgroups as follows:

Group I (normal control): The rats in this group were divided into three subgroups of five rats each as follows: Group Ia: Normal control group; the rats did not receive any medications for three successive 3 weeks and were then sacrificed. Group Ib: Normal control group; the rats did not receive any medications for six successive weeks and were then sacrificed. Group Ic: Normal control group; the rats did not receive any medications for nine successive weeks and were then sacrificed.

Group II (sham control): The rats in this group were divided into three subgroups of five rats each as follows: Group IIa: the rats were given normal saline orally by gastric tube for three successive weeks, and were then sacrificed. Group IIb: the rats were given normal saline orally by gastric tube for six successive weeks, and were then sacrificed. Group IIc: the rats were given normal saline orally by gastric tube for nine successive weeks, and were then sacrificed.

Group III (medical hypothyroidism group): The rats in this group were divided into three subgroups of five rats each as follows: Group IIIa (medical Hypothyroidism, short duration): the rats in this group were given Carbimazole orally by gastric tube in a dose of $0.05 \mathrm{mg} / \mathrm{kg}$ daily for three successive weeks, and then they were sacrificed 24 hours after the last dose (Dakine et al., 2000). Group IIIb (medical Hypothyroidism, long duration): the rats in this group were given Carbimazole daily for six successive weeks, and then they were sacrificed 24 hours after the last dose. Group IIIc (medical Hypothyroidism, recovery group): the rats of this group were given Carbimazole orally daily for six successive weeks then were left without any medication for another 3 weeks, and then they were sacrificed.

Group IV (L-Thyroxine supplemented group): The rats in this group were divided into two subgroups as follows: Group IVb (L-Thyroxine supplemented group, short duration): the rats in this group were given Carbimazole orally daily for three successive weeks then L-Thyroxine was given orally in a dose of $(10 \mu \mathrm{g} / 100 \mathrm{~g}$ bw) daily for another three successive weeks (El-Bassouny, 2012), then they were sacrificed 24 hours after the last dose of LThyroxine. Group IVc (L-Thyroxine supplemented group, long duration): the rats in this group were given carbimazole orally daily for six successive weeks, thereafter L-Thyroxine was given orally daily for three successive weeks (Dakine et al., 2000). The rats were then sacrificed after the last dose of L-Thyroxine.

At the end of the allowed experimental period for each group, the rats were sacrificed (without euthanasia, cervical decapitation method was used). Blood samples were rapidly collected from rat tail and used for biochemical examinations. The parotid glands were extracted from all animals and then prepared for histological study (light and electron microscopic study).

\section{Biochemical investigations}

The mean serum T3, T4 and TSH were measured in each group. This was done in the Biochemistry Department, Faculty of medicine, Cairo University (El-Wakf et al., 2009).

\section{Tissue preparation for histological study}

Light microscopic study: specimens were fixed in formol saline and were processed for paraffin sections of $5 \mu \mathrm{m}$-thick stained with (Bancroft and Gamble, 2008): (a) Hematoxylin and Eosin (Avwioro. 2010), to observe the parotid gland architecture; (b) Mallory's trichrome stain (Ross and Michael, 2011), to evaluate the collagen fibers; (c) Immunohistochemical Study (Bcl-2) (Kiernan, 2015) were carried out using the avidin biotin peroxidase system for localization of Bcl-2 protein. 


\section{Morphometric study}

This was carried out by using Leica Qwin 500 Image Analyzer Computer System. The percentage of the area of collagen tissue fibers in Mallory trichrome stained sections and Immunohistochemical optical density were examined.

\section{Statistical analysis}

The data obtained (serum total T3, serum total T4, serum TSH) and area percent of collagen for all groups were expressed as means $\left(\mathrm{X}^{-}\right)$ and standard deviations (SD) and subjected to statistical analysis using one-way analysis of variance (ANOVA) for comparison between the different groups (more than two groups). The level $\mathrm{P} \leq 0.05$ was considered the cut-off value for significance. All statistical analysis was done using the (SPSS) version 18 packages.

\section{RESULTS}

\section{Histological results}

Groups I and II: Light microscopic examination showed no observable difference in the histological findings between the normal and the sham control groups were noticed; sections of the parotid gland were composed of several lobes of different sizes. Each lobe comprised several lobules; consisted of numerous serous acini, lying close to one other and were separated by a fine network of an interacinar connective tissue. Each serous acinus was composed of cuboidal cells with basal rounded nuclei and narrow lumina with homogenous acidophilic cytoplasm (Fig. 1A, 1B). The striated ducts were lined by columnar cells with central rounded nuclei (Fig. 1A). Excretory interlobular ducts were present within the interlobular connective tissue, with wide irregular lumina and lined with pseudo stratified columnar epithelium (Fig. 1A, 1B). Blood vessels were seen in the connective tissue septa (Fig. 1A, 1B). Mallory's trichrome stained sections demonstrated a thin layer of collagen fibers present around the serous acini, blood vessels and the ducts (Fig. 2A, 2B). Immunohistochemical stained sections showed strong immune reaction for Bcl-2 in the cytoplasm of parotid cells (Fig. 3A, 3B). Electron microscopic examination of parotid gland sections of the control group showed serous acini with basal euchromatic nuclei and prominent nucleoli. Their cytoplasm presented many electron-lucent secretory granules (Fig. 4A, 4B). The nuclei of the acinar cells were surrounded by extensive rough endoplasmic reticulum (Fig. 4A).

Group IIIa: Hematoxylin and eosin-stained sections showed degenerative change in the form of some of serous acini which showed irregular outlines and were widely separated. Some acinar cells had deeply stained nuclei. Other acini appeared normal. Extravasated blood and cellular infiltration were also found in the interstitial space. The interlobular ducts and striated ducts appeared disrupted and dilated (Fig. 1C). Mallory's trichrome stained sections revealed apparently increased collagen fibers deposition in between lobules and around blood vessels (Fig. 2C). Immunohistochemical stained sections showed moderate expression of Bcl-2 protein in the cytoplasm of parotid gland cells and ducts (Fig. 3C) indicating damage caused by the drug. Electron microscopic examination showed condensed heterochromatic nucleus of the acinar cells, dilated rough endoplasmic reticulum and multiple cytoplasmic vacuolations; swollen mitochondria were seen and the rough endoplasmic reticulum was markedly dilated. Also, normal mitochondria with intact cristeal appearance could be detected (Fig. 4C). Group IIIb: Hematoxylin and eosin-stained sections showed marked degenerative changes than group IIIa; most of serous acini were atrophic with indistinct outline with mononuclear cellular infiltration. The cell cytoplasm was not uniformly stained and showed clear unstained vacuolar spaces. Dilated and congested blood vessels were also seen. Dilated irregular intercalated ducts were seen (Fig. 1D). Mallory's trichrome stained sections revealed extensive collagen fibers deposition more than group III a in between lobules and around blood vessels (Fig. 2D), indicating more destruction with longer duration. Immunohistochemical stained sections showed moderate (Fig. 3D) expression of Bcl-2 protein in the cytoplasm of parotid gland cells and ducts indicating more damage caused with longer duration. Electron microscopic 

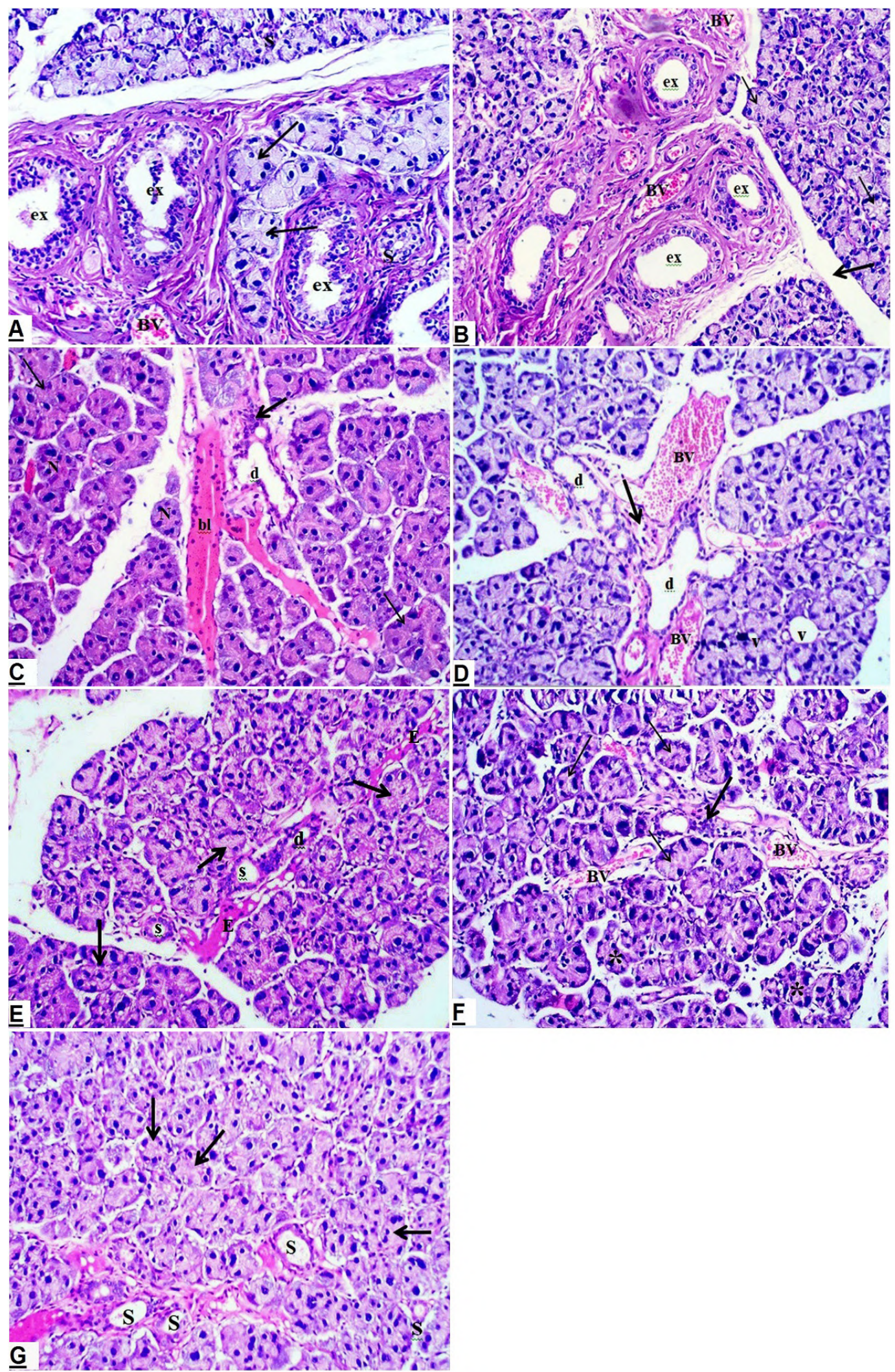

Fig. 1.- Sections of the parotid gland. A. group I showing normal serous acini (arrows) lined with cuboidal cells, striated duct(s) has rounded narrow lumen surrounded by simple columnar cells, excretory interlobular ducts (ex) have wide irregular lumina; lined with pseudo stratified columnar epithelium. Blood vessels (BV) are seen in the connective tissue septa; B. group II showing normal serous acini (thin arrows) composed of cuboidal cells with basal rounded nuclei and narrow lumens. Thin connective tissue septa in between the lobules (thick arrow) are seen rich in blood vessels (BV) and excretory interlobular ducts (ex) have wide irregular lumina; lined with pseudo stratified columnar epithelium; C. group IIIa showing the acini with irregular outlines (thin arrows). The cells of these acini contain darkly stained nuclei and others appear normal (N). Dilated intercalated duct (d), inflammatory cellular infiltration (thick arrow) and extravasated blood (bl) are seen; D. group IIIb showing cytoplasmic vacuoles (V) in the serous acini. Dilated irregular intercalated ducts (d), inflammatory cellular infiltration (thick arrow), and dilated congested blood vessels (BV) are seen. E. group IIIc showing apparently normal acini (arrows), striated ducts (s) and intercalated ducts (d). Interstitial hemorrhagic exudate (E) is present. F. group IVb showing serous acini regaining their normal architecture (thin arrows), others are irregular (star). Blood vessels (BV) are normal but inflammatory cells (thick arrow) could be detected. G. group IVc showing the serous acini restoring their normal architecture (arrows) and apparently normal striated ducts(S). Hematoxylin \& Eosin, x200. 

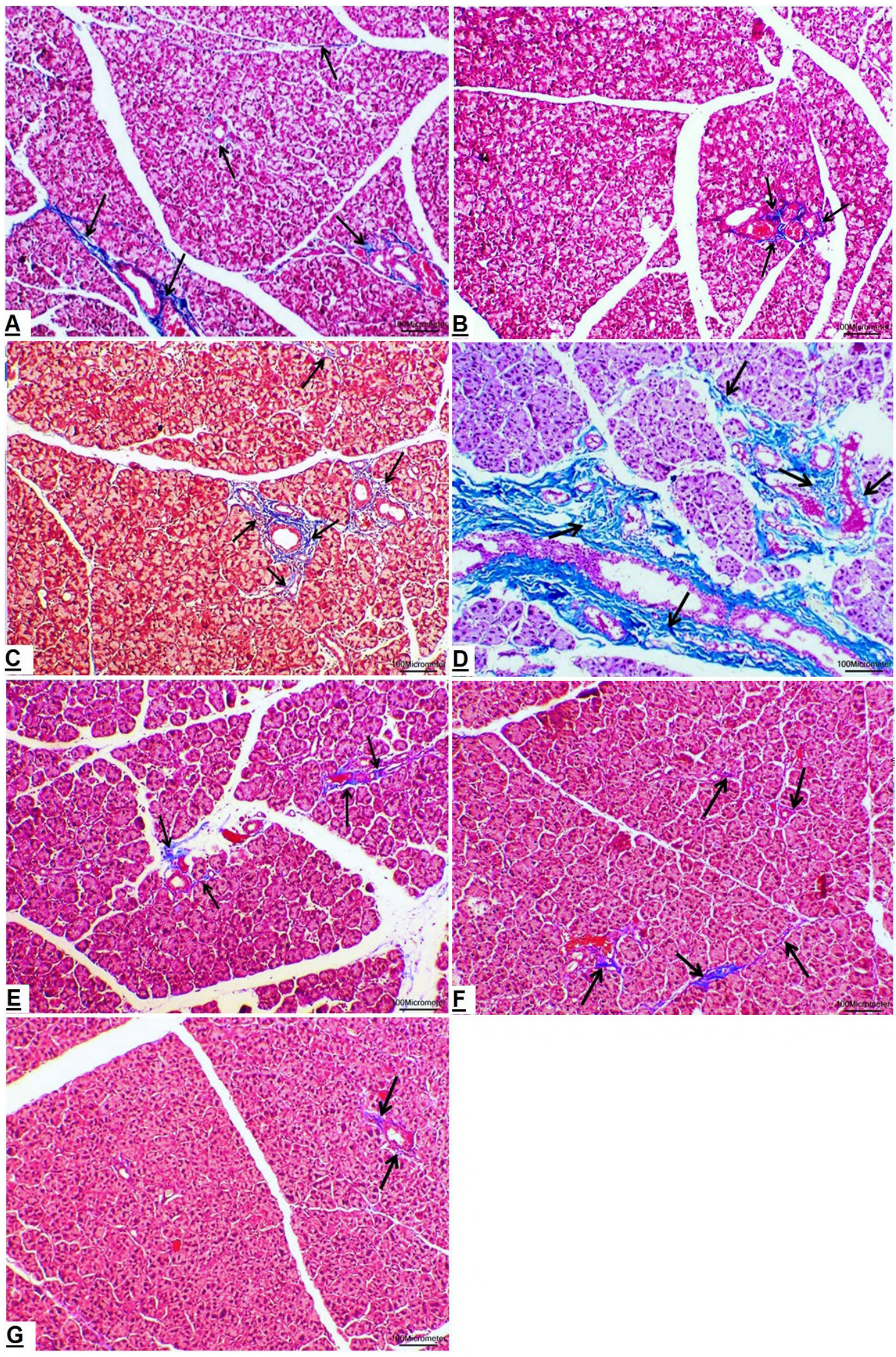

Fig. 2.- Sections of the parotid gland. A. showing thin layer of collagen fibers in between the lobules, around blood vessels and the ducts (arrows); $\mathbf{B}$ thin layer of collagen fibers around blood vessels and the ducts (arrows); C. increased collagen fibers deposition in between lobules and around blood vessels (arrows); D. collagen fibers deposition in wide areas between the lobules and around blood vessels (arrows); E. minimal amount of collagen fibers (arrows) in between the acini and around blood vessels. F and $\mathbf{G}$. minimal amount of collagen fibers in between the lobules and around blood vessels (arrows). Mallory T, x100. 

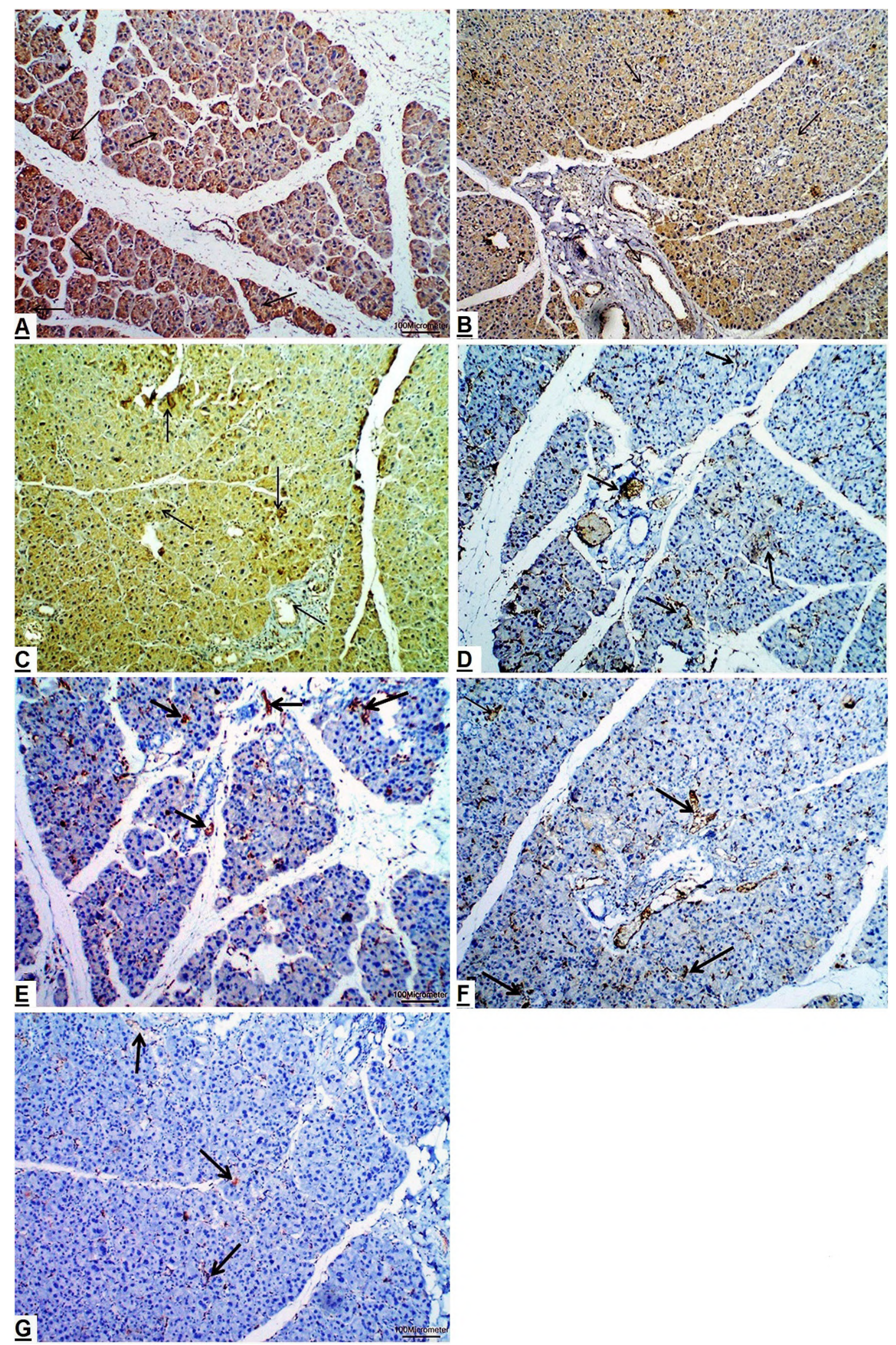

Fig. 3.- Sections of the parotid gland. A. intense expression of Bcl-2 protein in the cytoplasm of parotid gland cells (arrows). B. intense expression of Bcl-2 protein in the cytoplasm of parotid gland cells and ducts (arrows).; C. moderate expression. showing moderate expression; D. moderate expression of Bcl-2 protein in the cytoplasm of parotid gland cells and ducts (arrows). E. showing mild expression; F. moderate expression and G. weak expression of Bcl-2 protein in the cytoplasm of parotid gland cells and ducts (arrows). Immunohistochemistry, x100. 
examination showed that some acinar cells had multiple cytoplasmic vacuolations. Other cells showed apoptotic pyknotic nuclei (Fig. 4D). Group IIIc: Histological sections revealed an apparently normal parotid architecture with normal serous acini and ducts and the interstitial spaces were filled with hemorrhagic exudate indicating recovery stage of the parotid gland after stoppage of taking the drugs (Fig. 1E). Mallory's trichrome stained sections showed minimal collagen fibers deposition around blood vessels and striated ducts (Fig. 2E), indicating recovery stage. Immunohistochemical stained sections showed mild expression of Bcl-2 protein in the cytoplasm of parotid gland cells and ducts (Fig. $3 \mathrm{E})$, indicating that the parotid gland still healing. Electron microscopic study showed regaining of normal parenchymal architecture of the serous acini. Some of the acinar cells were apparently normal, with euchromatic nuclei and prominent nucleoli, while others still had pyknotic nuclei. The cytoplasm contained minimal cytoplasmic vacuoles. Others showed apparently normal rough endoplasmic reticulum with multiple electron lucent secretory granules. Normal mitochondria with intact membrane and cristae (Fig. 4E).

Group IVb: Histological sections revealed an improvement in the parenchymal architecture of the parotid gland. The structure of the duct system did not show any discernable change when compared with the control. The striated and the excretory ducts appeared with regular walls and narrow lumina (Fig. 1F). Mallory's trichrome stained sections showed collagen fibers were apparently decreased in comparison to group IIIa and IIIb around blood vessels and striated ducts (Fig. 2F), indicating starting recovery. Immunohistochemical stained sections showed moderate expression of $\mathrm{Bcl}-2$ protein in the cytoplasm of parotid gland cells and ducts (Fig. $3 \mathrm{~F})$, indicating recovery. Electron microscopic examination showed that most of acini were apparently normal with euchromatic nuclei surrounded with normal rough endoplasmic reticulum; the mitochondria appeared normal, with intact membrane. The cytoplasm contained few cytoplasmic vacuoles; multiple electron lucent and electron dense secretory granules could be seen (Fig. 4F). Group IVc: histological sections revealed an apparently normal parotid architecture (Fig. 1G). Mallory's trichrome stained sections showed apparently decreased in collagen fibers deposition mainly around blood vessels (Fig. 2G), indicating recovery. Immunohistochemical stained sections showed variable degrees of recovery; weak expression (Fig. $3 \mathrm{G}$ ) of Bcl-2 protein in the cytoplasm of parotid gland cells and ducts. Electron microscopic study showed preserved parenchymal architecture of the serous acini; the nuclei of the cells were basal euchromatic with prominent nucleoli. Regular intact nuclear envelope. The intercellular desmosomes were narrow and intact. Normal rough endoplasmic reticulum and electron lucent secretory granules could be seen (Fig. 4G).

\section{Histomorphometric results}

A - Mean percentage area of collagen fibers deposition (Fig. 5A - Table 1): Statistical analysis of data showed that there was no statistically significant difference in the mean area percent of collagen fibers between the control group I and sham control group II. Highly statistically significant increase in the mean area percent of collagen fibers of the parotid gland was detected in group III as compared to the control group and group IV. Group IIIb was highly significantly different compared to the control groups and IIIc, indicating more destruction. There was no statistically significant difference between group IV and control groups, but was significantly different compared to group III, indicating recovery. B - Mean optical density of Bcl-2 (Fig. 5B - Table 2): Statistical evaluation of the mean values of the Bcl-2 optical density in the different experimental groups showed no statistically significant difference between the control group I and sham control group II. Statistical evaluation showed highly significant decrease in mean optical density in group III compared to control groups. The difference in group IIIb was statistically lower as compared to the control groups, group IIIa and IIIc, while the mean values in group IV showed no significant difference compared to control groups. C Statistical analysis of the mean T3, T4, TSH (Figs. 5C, D, E - Tables 3, 4, 5): Statistical evaluation of the 

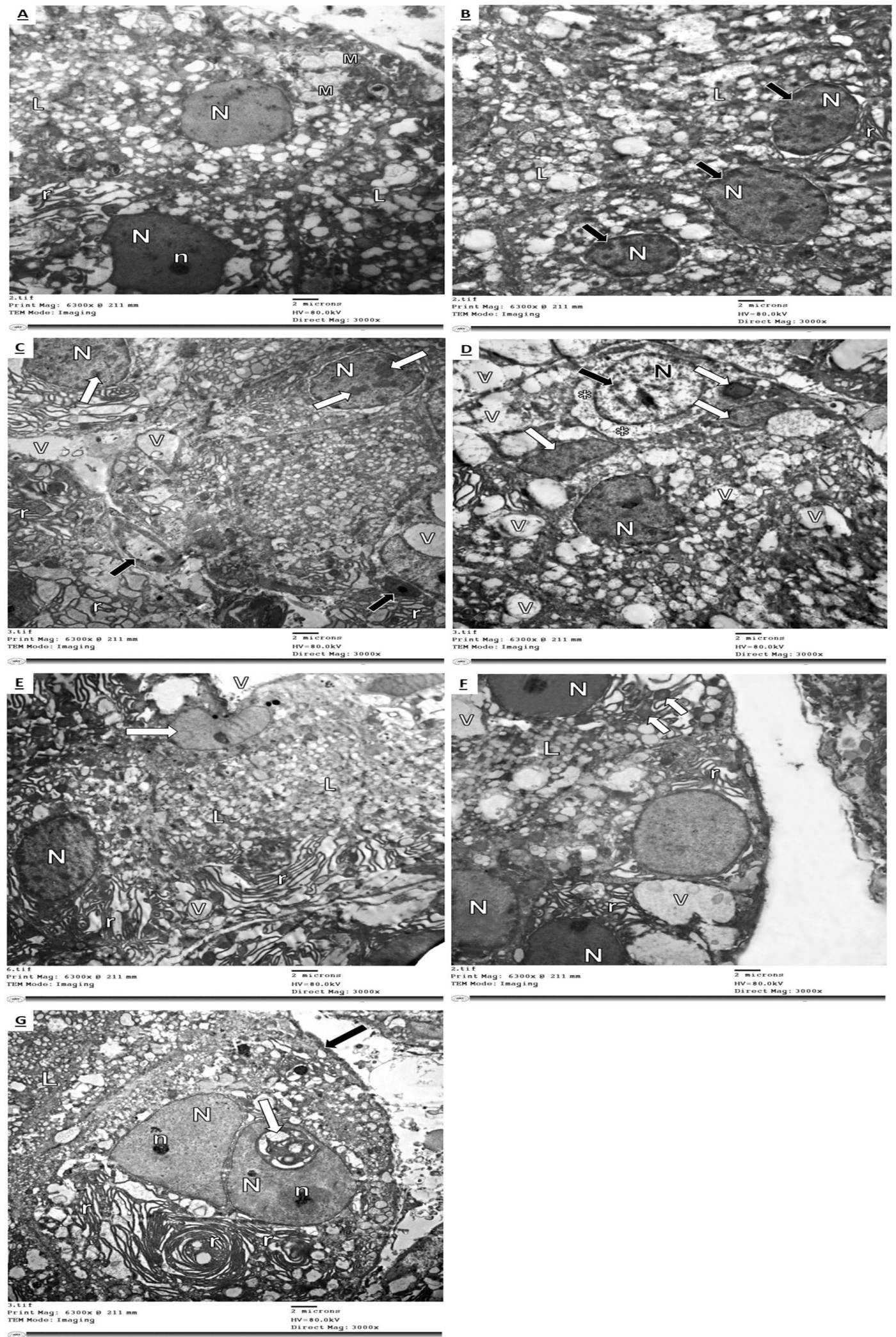

Fig. 4.- Electron micrographs of the parotid gland. A. an acinar cell with euchromatic nucleus (N) and prominent nucleolus (n), abundant rough endoplasmic reticulum (r) and many electron-lucent (L) secretory granules. Intact and prominent mitochondria (M) are present; B. acinar cell with euchromatic nucleus (N), intact nuclear membranes (arrows) and many electron-lucent (L) secretory granules. The cell cytoplasm is rich in mitochondria (M); C. acinar cells containing irregular heterochromatic nuclei (N) with chromatin clumps (white arrows). Shrunken condensed nuclei (black arrow) surrounded by dilated rough endoplasmic reticulum (r). Cytoplasmic vacuoles (V) are also seen; D. acinar cells with irregular heterochromatic nucleus (white N), some nuclei (black N) containing clumped chromatin material (black arrow) surrounded by rarified cytoplasm (*), other nuclei are condensed and shrunken (white arrows). Multiple cytoplasmic vacuoles (V) are seen; E. acinar cell with shrunken irregular nucleus (white arrow), other one heterochromatic nucleus $(\mathrm{N})$, extensive electron-lucent secretory granules $(\mathrm{L})$, apparently normal rough endoplasmic reticulum (r) and few vacuoles (V) could be detected. F. normal euchromatic nuclei (N) surrounded by normal rough endoplasmic reticulum (r), normal mitochondria (white arrows) and multiple electron-lucent (L) secretory granules. Few vacuoles could be detected (V); $\mathbf{G}$ apparently normal basal nuclei (N) with prominent nucleolus (n), but vacuolation within the nucleus could be detected (white arrow), surrounded by normal rough endoplasmic reticulum (r) with electron-lucent granules (L). The cell membrane is well defined (black arrows). Scale bars $=2 \mu \mathrm{m}, \mathrm{x} 5000$ 
mean values of the T3, T4, and TSH in the different experimental groups showed no statistically significant difference between the control group I and sham control group II. Highly statistically significant decrease in the mean values of total $\mathrm{T} 3$ and total $\mathrm{T} 4$ and increase in the mean values of TSH was detected in the hypothyroid group (G III) compared to the control groups. Significant increase in the mean values of total T3 and total $\mathrm{T} 4$ and significant decrease in the mean values of TSH in L-Thyroxin supplemented group (G VI) were observable when compared to those of hypothyroid group (G III). However, there was no statistically significant difference in the mean values of the T3, T4, and TSH between group IV and control groups.
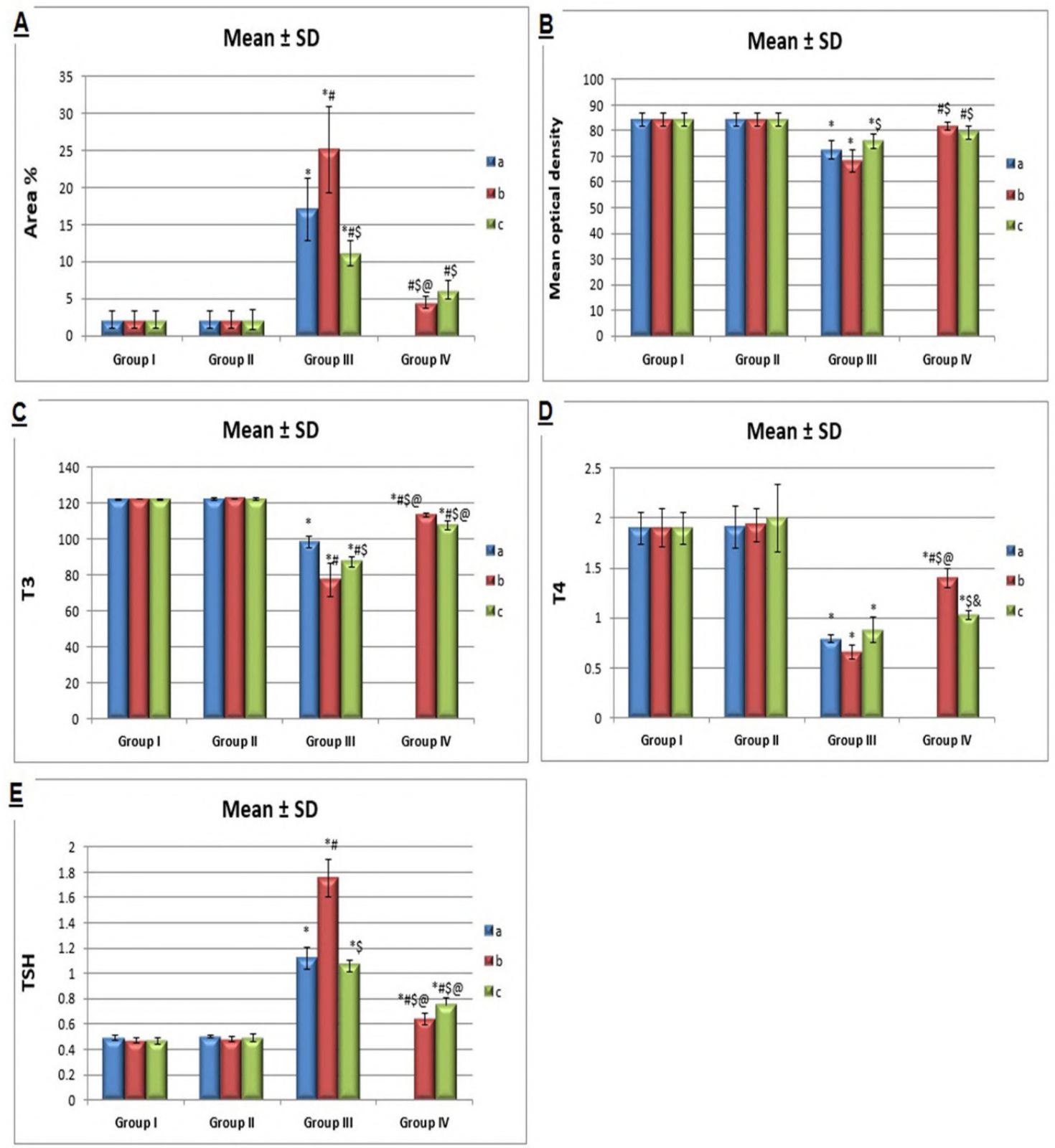

Fig. 5.- Histograms displaying: A: no statistically significant difference in the mean area percent of collagen fibers between the control group I and sham control group II. Highly statistically significant increase in the mean area percent of collagen fibers of the parotid gland was detected in group III as compared to the control group and group IV. Group IIIb was highly significant different compared to the control groups IIIa and IIIc; indicating more destruction. No statistically significant difference between group IV and control groups but was significant different compared to group III, indicating recovery; B: Statistical evaluation of the mean values of the Bcl-2 optical density showed no statistically significant difference between the control and sham control group. Statistical evaluation showed high significant decrease in mean optical density in group III compared to control groups. The difference in group IIIb was statistically lower as compared to the control groups, group IIIa and IIIc, while the mean values in group IV showed no significant difference compared to control groups; C, D and E: Statistical evaluation of the mean values of the T3, T4, and TSH showed no statistically significant difference between the control and sham control group. Highly statistically significant decrease in the mean values of total T3 and total T4 and increase in the mean values of TSH was detected in group III as compared to the control groups. Significant increase in the mean values of total T3 and total T4 and significant decrease in the mean values of TSH in group VI when compared to those of group III. However, there was no statistically significant difference in the mean values of the T3, T4, and TSH between group IV and control groups. 
Table 1. The mean area percent of collagen fibers in all groups using ANOVA test: $p$-value is significant $\leq 0.05$.

\begin{tabular}{|c|c|c|c|c|}
\hline Area \% & Group I & Group II & Group III & Group IV \\
\hline $\mathbf{a}$ & $2.13 \pm 1.18$ & $2.13 \pm 1.19$ & $16.99 \pm 4.23$ & \\
\hline b & $2.09 \pm 1.17$ & $2.11 \pm 1.18$ & $25.08 \pm 5.81$ & $4.54 \pm 0.84$ \\
\hline c & $2.19 \pm 1.22$ & $2.21 \pm 1.31$ & $11.18 \pm 1.66$ & $6.2 \pm 1.19$ \\
\hline \multicolumn{5}{|l|}{ P-values } \\
\hline G IIIa vs. G IIIb & & & $<0.0001$ & \\
\hline G IIIb vs. G IIIc & & & $<0.0001$ & \\
\hline G IIIa vs. G IVb & & & & $<0.0001$ \\
\hline G IIIb vs. G IVc & & & & $<0.0001$ \\
\hline G IIIc vs. G IVc & & & & 0.075 \\
\hline
\end{tabular}

Table 2. The mean Bcl-2 optical density in all groups using ANOVA test: $p$-value is significant $\leq 0.05 p$-value is highly significant $\leq 0.01$

\begin{tabular}{|l|l|l|l|l|}
\hline Mean Opt Density & Group I & Group II & Group III & Group IV \\
\hline \multicolumn{1}{|c|}{ a } & $84.27 \pm 2.38$ & $84.26 \pm 2.37$ & $\mathbf{7 2 . 5 2} \pm \mathbf{3 . 4 4}$ & \\
\hline c & $84.27 \pm 2.41$ & $84.27 \pm 2.42$ & $\mathbf{6 8 . 2 1} \pm \mathbf{4 . 4}$ & $81.72 \pm 1.57$ \\
\hline P-values & $84.27 \pm 2.44$ & $84.28 \pm 2.44$ & $\mathbf{7 5 . 8 6} \pm \mathbf{2 . 7 8}$ & $79.35 \pm 2.56$ \\
\hline G IIIa vs. G IIIb & & & & 0.343 \\
\hline G IIIb vs. G IIIc & & & $\mathbf{0 . 0 0 3}$ & $<0.0001$ \\
\hline G IIIa vs. G IVb & & & & $<\mathbf{0 . 0 0 0 1}$ \\
\hline G IIIb vs. G Ivc & & & & 0.64 \\
\hline G IIIc vs. G Ivc & & & & \\
\hline
\end{tabular}

Table 3. The mean T3 in all groups using ANOVA test: $p$ - Value is significant $\leq 0.05 p$-value is highly significant $\leq 0.01$

\begin{tabular}{|c|c|c|c|c|}
\hline T3 & Group I & Group II & Group III & Group IV \\
\hline $\mathbf{a}$ & $122.28 \pm 0.42$ & $122.34 \pm 0.48$ & $98.36 \pm 3.26$ & \\
\hline b & $122.34 \pm 0.27$ & $122.4 \pm 0.16$ & $77.36 \pm 9.05$ & $113.46 \pm 1.1$ \\
\hline c & $122.32 \pm 0.33$ & $122.18 \pm 0.65$ & $87.36 \pm 2.86$ & $107.6 \pm 2.47$ \\
\hline \multicolumn{5}{|l|}{ P-values } \\
\hline G IIIa vs. G IIIb & & & $<0.0001$ & \\
\hline G IIIa vs. G IVb & & & & $<0.0001$ \\
\hline G IIIb vs. G IVc & & & & $<0.0001$ \\
\hline G IIIc vs. G IVc & & & & $<0.0001$ \\
\hline G IVb vs. G IVc & & & & 0.143 \\
\hline G IIIb vs. G IVc & & & & $<0.0001$ \\
\hline
\end{tabular}


Table 4. The mean T4 in all groups using ANOVA test: $p$-value is significant $\leq 0.05 p$-value is highly significant $\leq 0.01$

\begin{tabular}{|c|c|c|c|c|}
\hline T4 & Group I & Group II & Group III & Group IV \\
\hline $\mathbf{a}$ & $1.9 \pm 0.16$ & $1.91 \pm 0.21$ & $0.79 \pm 0.04$ & \\
\hline b & $1.9 \pm 0.19$ & $1.93 \pm 0.16$ & $0.66 \pm 0.07$ & $1.4 \pm 0.1$ \\
\hline c & $1.9 \pm 0.16$ & $2 \pm 0.34$ & $0.88 \pm 0.13$ & $1.03 \pm 0.04$ \\
\hline \multicolumn{5}{|l|}{ P-values } \\
\hline G IIIa vs. G IIIb & & & 0.969 & \\
\hline G IIIa vs. G IVb & & & & $<0.0001$ \\
\hline G IIIb vs. G IVc & & & & 0.035 \\
\hline G IIIc vs. G IVc & & & & 0.941 \\
\hline G IVb vs. G IVc & & & & 0.039 \\
\hline G IIIb vs. G IVc & & & & 0.035 \\
\hline
\end{tabular}

Table 5. The mean TSH in all groups using ANOVA test: $p$-value is significant $\leq 0.05 p$-value is highly significant $\leq 0.01$

\begin{tabular}{|c|c|c|c|c|}
\hline TSH & Group I & Group II & Group III & Group IV \\
\hline $\mathbf{a}$ & $0.49 \pm 0.02$ & $0.5 \pm 0.01$ & $1.12 \pm 0.09$ & \\
\hline $\mathbf{b}$ & $0.47 \pm 0.02$ & $0.48 \pm 0.02$ & $1.75 \pm 0.15$ & $0.64 \pm 0.05$ \\
\hline c & $0.47 \pm 0.02$ & $0.49 \pm 0.03$ & $1.07 \pm 0.03$ & $0.75 \pm 0.06$ \\
\hline \multicolumn{5}{|l|}{ P-values } \\
\hline G IIIa vs. G IIIb & & & $<0.0001$ & \\
\hline G IIIa vs. G IVb & & & & $<0.0001$ \\
\hline G IIIb vs. G IVc & & & & $<0.0001$ \\
\hline G IIIc vs. G IVc & & & & $<0.0001$ \\
\hline G IIIb vs. G IIIc & & & $<0.0001$ & \\
\hline
\end{tabular}

\section{DISCUSSION}

THs have wide range of effects on multi organ systems of the human body. They are responsible for control of normal functions of nearly all tissues with prominent effects on thermogenesis, lipogenesis and oxygen consumption (Shi et al., 2002). Also, an association between thyroid dysfunction and a significant decrease in salivary parameters such as flow rate and buffering capacity had been confirmed (Muralidharan et al., 2013). It had also been reported that lack of THs provoked physiological and histological changes in the submandibular, sublingual and parotid glands respectively (Noorafshan, 2001). Previous studies proved that thyroid gland rendered hypofunctional when treated with hypothyroid drugs (Hayat et al., 2010). It was postulated that the hypothyroid drug acts as a false substrate for thyroid peroxidase, thus blocking the iodination of tyrosine residues within thyroglobulin (ČakićMilošević et al., 2004).

In our experimental model, development of hypothyroidism was confirmed both by histological changes in the parotid gland and estimation of serum levels of T3, T4 and TSH. Significant decrease in T3, T4 and increase in TSH serum levels were indicative that the quantity and duration of treatment was sufficient to induce hypothyroid status in the experimental group of rats. Examination of the medical Hypothyroidism, short duration group showed that most of the serous acini had irregular outlines and were widely separated. Some acinar cells contained darkly stained and hyperchromatic nuclei, with narrow lumen and cytoplasmic vacuoles. Extravasated blood, dilatation of the duct system and cellular 
infiltration were seen in the interstitial space; these were in line with the results of Abd Elazeem et al. (2016), who found that parotid parenchyma contained many serous acini and most of them had irregular outlines. The salivary glands atrophy observed in this study could explain the decreased salivary flow rate that was previously documented in hypothyroid rats in the study of Rodriguez et al., (2009), who stated that hypothyroidism was caused by propylthiouracil, a thyroperoxidase activity inhibitor, consequently inhibiting thyroid hormone biosynthesis and reduced the salivary flow in injected rats, in comparison with the euthyroid control rats. In our present study, the nuclei of parotid gland cells were darkly stained in the experimental animals of the hypothyroid groups. The same results were obtained by Ashour (1998), who reported that the amount of euchromatin was used as an indicator of the metabolic activity of cells; conversely a high proportion of heterochromatin indicates a cell with low metabolic activity.

Increased collagen fibers deposition in the parotid gland of the hypothyroid groups were observed in the present study around congested blood vessels compared to the control group in Mallory's trichrome stained sections. Those results were online with Hayat et al. (2010) and Abd Elazeem et al. (2016), who clarified the presence of extensive collagen fibers in between lobules, around blood vessels and interlobular ducts in parotid gland of hypothyroid rats for short duration. Examination of the medical hypothyroidism, long duration showed more destruction, atrophic serous acini with irregular arrangement. The aciniwere divided by connective tissue septa, which were markedly thick. During examination of the medical hypothyroidism, group III c and group IV showed apparently normal parotid architecture with normal serous acini and ducts. The same results were in line with Abd Elazeem et al. (2016), who found sections of parotid gland of thyroid hormone supplemented group for short duration, showing that most of acini and ducts were apparently normal, while some acini had an irregular outline. Some acinar cells still contained vacuolated cytoplasm.

Microscopic findings of the parotid glands of hypothyroid rat showed atrophy of acini and partial replacement of the parenchyma with a connective tissue component. The same results were obtained by Oncu et al. (2004) in the sublingual gland of rats after thyroidectomy, in addition to cytoplasmic vacuolization of the epithelial cells, enlargement and dilatation of lumina in most of the gland. This is probably due to severe hypothyroidism, increased mucous secretion, lipid tissue mass surrounding the parenchyma and mononuclear cell infiltration. Markitziu et al. (1993) reported that thyroidectomy caused hypercholesterolemia and fatty degeneration of the parotid parenchyma, which was in line with our findings in the parotid of hypothyroid groups.

In the current work, Mallory's trichrome stained sections clarified the presence of extensive collagen fibers in parotid glands of group IIIb more than in IIIa, indicating more destruction with increased duration, while collagen fibers were apparently decreased in group IIIc and group VI in comparison to group IIIa and IIIb. These finding were in agreement with Abd Elazeem et al. (2016), who showed amelioration of most degenerative changes that occurred in the parotid gland after treatment with L-Thyroxin.

ROS are by-products of normal metabolism in all aerobic cells. Most of the oxygen consumed by the cells is reduced to water during mitochondrial respiration. A sensitive balance exists between ROS production and the antioxidant defenses that protect the cells in vivo (Halliwell and Gutteridge, 2015). It has been observed that a change in thyroid gland function affects production of ROS in rats (Venditti and Di Meo, 2006). It has also been reported that hypothyroidism alters the antioxidant defense system in various tissues (Cattani et al., 2013) and thyroid dysfunction appears to be closely related to ROS formation as reported by Ahmed et al. (2012). In support to our results, some of the studies reported that hypothyroidism conditions change the activity of the antioxidant status in several tissues including the brain (Jena et al., 2012). The same results were obtained by Abou-Elghaita et al. (2011), who stated that thyroid deprivation causes changes in the levels of lipid peroxidation and antioxidant enzyme activities which were determined in different tissues of hypothyroid rats, causing 
the functional disorder of these tissues. Pan et al. (2017) found that lipid peroxidation level was elevated while antioxidant defense enzymes levels were decreased in the hippocampus of hypothyroid rats. These findings and the results of the present study may suggest an imbalance between oxidant and antioxidant system as a leading factor to the parotid gland's oxidative damage in hypothyroidism.

Examination of ultrathin sections of the hypothyroid group showed acinar cells with irregular heterochromatic nuclei, dilated rough endoplasmic reticulum, degenerated mitochondria and cytoplasmic vacuoles, with more destructive changes in group IIIb than in IIIa. These structural changes were consistent with Yang et al. (2015), who found similar changes in the hippocampus of hypothyroid rats induced by propylthiouracil for 4 weeks: there were margination of nuclear chromatins; a lot of mitochondria were swollen, the cristae broke and showed significant vacuolar degeneration; the rough endoplasmic reticulum and ribosomes were obviously sparse. While the T4 injected group for 2 weeks exhibited clear nuclear membranes, the organelles were relatively sparse and a small amount of mitochondria exhibited vacuolation; rough endoplasmic reticulum was mildly dilated and in line with Abd Elazeem et al. (2016), who found that some acinar cells had irregular heterochromatic nuclei. Their cytoplasm contained markedly dilated rough endoplasmic reticulum. Some acinar cells showed variably sized vacuoles in their cytoplasm. Other cells showed apoptotic nuclei in parotid gland of hypothyroid rats after treatment with Carbimazole for successive 3 weeks. These changes were improved after induction of L-Thyroxin and in recovery group, which showed an apparently normal parotid architecture with normal serous acini and ducts.

Other areas showed acini with irregular walls and few cytoplasmic vacuoles, the interstitial spaces were wide, edematous and filled with hemorrhagic exudate, indicating healing of the parotid gland after stoppage taking the drugs. These results were in agreement with Abd Elazeem et al. (2016), after treatment with L-Thyroxin for successive 3 weeks. Cell apoptosis is orderly death of the cell by genes controlled, which control the stability of the internal environment. Recent studies (Pan et al., 2017) have found that apoptosis is closely related to the occurrence and development of many diseases. Bcl-2 family proteins play an important role in cell apoptosis (Hardwick and Soane, 2013). This hypothyroidism-induced acinar cell death was assumed to be due to apoptosis, which was supported in our study by the presence of shrunken dark irregular acinar nuclei in addition to chromatin clumping in some acinar nuclei (Takahashi et al., 2005).

In the current work, immunohistochemical examination for Bcl-2 was performed. In the control groups, immunohistochemical stained sections showed strong immune reaction for Bcl-2 in the cytoplasm of parotid cells and within the ducts. Concerning hypothyroid groups, weak immune reaction for $\mathrm{Bcl}-2$ in the cytoplasm of parotid cells was detected. While immunohistochemical examination for Bcl-2 of L-Thyroxin-supplemented groups and recovery group revealed moderate reaction in the cytoplasm of parotid cells and ducts. These finding were in agreement with Abd Elazeem et al. (2016) in control, hypothyroid group and L-Thyroxinsupplemented group for short duration on parotid gland. The same results were obtained by Muller et al. (1995), who suggested that THs deficiency results in delayed proliferation and migration of cerebellar granule cells. They evaluated the effect of hypothyroidism on Bcl-2 family gene expression in the developing rat cerebellum. Muller et al. (1995) suggested that normal levels of THs prevent cerebellar apoptosis to a large extent, whereas hypothyroidism not only increases the extent but also the duration of apoptosis by downregulating the anti-apoptotic genes Bcl-2 and maintaining a high level of the pro-apoptotic gene Bax (Liu et al., 2017). Several researchers have suggested that the THs are important in the maintenance of normal salivary gland function and histology (Oncu et al., 2004).

In our study, supplementation of thyroid hormone in the form of exogenous T4 significantly improved the histological changes that occurred in the parotid gland, which was in agreement with 
Abd Elazeem et al. (2016), who found improvement in Carbimazole induced hypothyroidism in rats' parotid glands treated with L-Thyroxin. From the collective data of the present study, it can be concluded that hypothyroidism exerts adverse effects on the rat's parotid gland, which can be ameliorated by administration of thyroid drugs (Muralidharan et al., 2013). The beneficial effects of thyroid hormones in the parotid gland became more obvious with increased duration.

\section{ACKNOWLEDGEMENTS}

I would like to express my deepest gratitude to Prof. Dr. Abd- Elwakeel Elsayed Essawy, Professor of Anatomy and Embryology, Faculty of Medicine, Cairo University, for his continuous encouragement and helpful advice, which contributed so much to bringing out this paper degree in an elegant and scientific form. It is my great honor to express my profound appreciation and sincere gratefulness to Dr. Gamal Hosny Mohammed, Assistant Professor of Anatomy and Embryology, Faculty of Medicine, Cairo University, for his valuable supervision and generous support. I would like to convey my discerning feeling of indebtedness to Dr. Ramadan Moustafa Elsayed, Lecturer of Anatomy and Embryology, Faculty of Medicine, Fayoum University and Dr. Ahmed Hamed Bayoumi, Lecturer of Anatomy and Embryology, Faculty of Medicine, Cairo University, for their continuous support and guidance.

\section{REFERENCES}

ABD ELAZEEM A, MOHAMMED MZ, HASSAN EZ (2016) Effect of experimentally induced hypothyroidism on the parotid gland of adult male albino rats and the possible role of thyroid hormone supplementation. Brit J Sci, 14(1): 19-36.

ABOU-ELGHAITA AT, RATEBB A, MAHMOUDB FY, GALAL O (2011) Effect of experimentally induced hypothyroidism during pregnancy and lactation on the retina of juvenile and adult albino rats and the possible role of thyroid hormone supplementation. Egypt J Hist, 34(1): 28-45.

AHMED OM, AHMED RG, EL-GAREIB AW, EL-BAKRY AM, ABD EL-TAWAB SM (2012) Effects of experimentally induced maternal hypothyroidism and hyperthyroidism on the development of rat offspring: II- The developmental pattern of neurons in relation to oxidative stress and antioxidant defense system. Int J Dev Neurosci, 30(6): 517-537.

ASHOUR MA (1998) Long-term effect of melatonin on submandibular salivary glands in old rats. Eastern Med Health J, 4(2): 324-331.

AVWIORO OG (2010) Histochemistry and tissue pathology, principles and techniques. North Am J Med Sci, 2(5): 561-568.
BANCROFT J, GAMBLE M (2008) Hematoxylins and Eosin. In: Bancroft J, Gamble M (eds). Theory and Practice of Histological Techniques. Churchill Livingstone, $6^{\text {th }}$ edition, pp 121-134.

BASAÑEZ G, HARDWICK JM (2008) Unravelling the Bcl-2 apoptosis code with a simple model system. PLoS Biol, 6(6): 154.

BHANJA S, CHAINY GBN (2010) PTU-induced hypothyroidism modulates antioxidant defense status in the developing cerebellum. Int J Dev Neurosci, 28(3): 251-262.

ČAKIĆ-MILOŠEVIĆ M, KORAĆ A, DAVIDOVIĆ V (2004) Methimazoleinduced hypothyroidism in rats: Effects on body weight and histological characteristics of thyroid gland. Jugoslovenska medicinska biohemija J, 23(2): 143-147.

CATTANI D, GOULART PB, CAVALLI VL (2013) Congenital hypothyroidism alters the oxidative status, enzyme activities and morphological parameters in the hippocampus of developing rats. Mol Cell Endocrinol, 375(1-2): 14-26.

DAKINE N, OLIVER C, GRINO M (2000) Effects of experimental hypothyroidism on the development of the hypothalamo-pituitaryadrenal axis in the rat. Life Sci, 67(23): 2827-2844.

DONG BJ (2004) Thyroid and anti-thyroid drugs. In: Green SFS, Dong BJ (eds). Basic and clinical pharmacology, $9^{\text {th }}$ edition, pp 625-640.

EL-BASSOUNY DR (2012) Ultrastructural study of the adult albino rat parotid gland with special reference to the role of stromal telocytes. Egypt J Hist, 35(4): 761-772.

EL-WAKF AM, HASSAN HA, ELSAID FG, EL-SAID A (2009) Hypothyroidism in male rats of different ages exposed to nitrate polluted drinking water. Res J Med Med Sci, 4(2): 160-164.

FULOP M (1989) Pouting sublingual: enlarged salivary glands in myxedema. Lancet, 2(2): 550-551.

HALLIWELL B, GUTTERIDGE JMC (2015) Ageing, nutrition, disease and therapy: a role for antioxidants. In: Halliwell B, Gutteridge JMC (eds). Free Radicals in Biology and Medicine, $5^{\text {th }}$ edition, pp 861-871.

HARDWICK JM, SOANE L (2013) Multiple functions of Bcl-2 family proteins. Cold Spring Harb Perspect Biol, (2): 1-5.

HAYAT NQ, TAHIR M, MUNIR B, SAMI W (2010) Effect of methimazoleinduced hypothyroidism on histological characteristics of parotid gland of albino rat. J Ayub Med Coll Abbottabad, 22(3): 22-27.

JENA S, CHAINY GBN, DANDAPAT J (2012) Hypothyroidism modulates renal antioxidant gene expression during postnatal development and maturation in rat. Gen Comp Endocrinol, 178(1): 8-18.

KHALAWI AA, AL-ROBAI AA, KHOJA SM, ALI SS (2013) Can Nigella Sativa Oil (NSO) reverses hypothyroid status induced by PTU in rat? Biochemical and histological studies. Life Sci J, 10(2): 802-811.

KIERNAN JA (2015) Theory and Practice. In: Kiernan JA (ed) Histological and Histochemical Methods. Scion, $5^{\text {th }}$ edition, pp 571-591.

LAMFON HA (2014) Effect of selenium on chlorpyrifos-induced thyroid toxicity in albino rats. IBIMA, 33(3): 441-450.

LIU Y, LIU YL, CHENG W, YIN XM, JIANG B (2017) The expression of SIRT3 in primary hepatocellular carcinoma and the mechanism of its tumor suppressing effects. Eur Rev Med Pharmacol Sci, 21: 978-998.

MARKITZIU A, LUSTMANN J, UZIELI B, KRAUSZ Y, CHISIN R (1993) Salivary and lacrimal gland involvement in a patient who had undergone a thyroidectomy and was treated with radioiodine for thyroid cancer. Oral Surg Oral Med Oral Pathol, 75(3): 318-322.

MULLER Y, ROCCHI E, LAZARO JB, CLOS J (1995) Thyroid hormone promotes Bcl-2 expression and prevents the apoptosis of early differentiating cerebellar granular neurons. Int J Dev Neurosci, 13(8): 871-885.

MURALIDHARAN D, FAREED N, PRADEEP PV, MARGABANDHU S, RAMALINGAM K, AJITH KBV (2013) Qualitative and quantitative changes in saliva among patients with thyroid dysfunction prior to and following the treatment of the dysfunction. Oral Surg Oral Med Oral Pathol Oral Radiol, 115(5): 617-623. 
NOORAFSHAN A (2001) Stereological study on the submandibular gland in hypothyroid rats. APMIS, 109(3): 223-227.

ONCU M, KANTER M, GOKCIMEN A, KAVAKLI D (2004) Effect of thyroidectomy on the histology of rat sublingual gland. APMIS, 112(2): 119-122.

PAN LJ, WANG X, LING Y, GONG H (2017) MiR-24 alleviates cardiomyocyte apoptosis after myocardial infarction via targeting BIM. Eur Rev Med Pharmacol Sci, 21(13): 3088-3097.

PETRULEA MS, DUNCEA I, MURESAN A (2009) Thyroid hormones in excess induce oxidative stress in rats. Acta Endocrinologica, 5(2): 155164.

PORTH CM, GASPARD K, GUVEN S, KUENZI JA, MATFIN (2004) Alterations in pituitary, thyroid, parathyroid and adrenal function. In: Porth CM, Grossman SC (eds). Porth's pathophysiology, concept of altered health states. Lippincott Williams \& Wilkins, $9^{\text {th }}$ edition, pp 538-559.

PUCCI E, CHIOVATO L, PINCHERA A (2000) Thyroid and lipid metabolism. Int J Obes Relat Metab Disord, 24(2): 109-112.

SHI YB, RITCHIE JWA, TAYLOR PM (2002) Complex regulation of thyroid hormone action: multiple opportunities for pharmacological intervention. Pharmacol Ther, 94(3): 235-251.

TAKAHASHI S, NAKAMURA S, DOMON T, YAMAMOTO T, WAKITA M (2005) Active participation of apoptosis and mitosis in sublingual gland regeneration of the rat following release from duct ligation. J Mol Histol, 36(3): 199-205.

RAJAB NMA, UKROPINA M, MILOSEVIC MC (2017) Histological and ultrastructural alterations of rat thyroid gland after short term treatment with high doses of thyroid hormones. Saudi J Biol Sci, 24(6): 1117-1125.

RODRIGUEZ TT, DANTAS VTA, RAMALHO MJP (2009) Participation of nitric oxide synthase and cyclooxygenase- 2 in the salivary secretion of hypothyroid endotoxemic rats. J Dental Sci, 24(4): 383-388.

ROSS MH, PAWLINA W (2011) Digestive system I: oral cavity and associated structures- In: Ross MH, Pawlina W (eds). Histology. A Text and Atlas with correlated cell and molecular biology. Wolters Kluwer/Lippincott Williams \& Wilkins Health, $6^{\text {th }}$ edition, pp 327-330, 402-407.

VAIDYA B, PEARCE SH (2008) Management of hypothyroidism in adults. BMJ, 337: 284-289.

VENDITTI P, DI MEO S (2006) Thyroid hormone-induced oxidative stress. Cell Mol Life Sci, 63(4): 414-434.

YANG H, ZHA X, CAI Y, WANG F, WU Z, WU B, JIA X, ZHU D (2015) Impacts of thyroxine combined with donepezil on hippocampal ultrastructures and expressions of synaptotagmin-1 and SNAP-25 in adult rats with hypothyroidism. Int J Clin Exp Med, 8(10): 17922-17931. 